\title{
Enantioselective Construction of Spirocyclic Oxindolic Cyclopentanes by Palladium-Catalyzed Trimethylenemethane-[3 +2]-Cycloaddition
}

\author{
Barry M. Trost, Nicolai Cramer, and Steven M. Silverman \\ Department of Chemistry, Stanford University, Stanford, California 94305-5080.
}

\begin{abstract}
The transition metal-catalyzed [3+2] trimethylenemethane (TMM) cycloaddition is a powerful and versatile method for the construction of cyclopentanes. ${ }^{1} \mathrm{Pd}-\mathrm{TMM}$ complexes generated from 3-acetoxy-2-trimethylsilylmethyl-1-propene and catalytic amounts of palladium react with electron deficient olefins to produce exo-methylenecyclopentanes in a highly chemo-, regio-, and diastereoselective manner. ${ }^{2}$ The ubiquity of cyclopentane containing natural products makes the development of an efficient asymmetric process highly desirable. However, applications of this methodology in asymmetric catalysis are very rare. ${ }^{3}$ Our ongoing efforts towards the synthesis of complex oxindole alkaloids prompted us to investigate the reactivity of 3-alkylidene-oxindoline-2-ones 1 towards Pd-TMM complexes. ${ }^{4}$ We chose the cyanosubstituted TMM-precursor 2,5 reasoning it could enhance the asymmetric induction.

Furthermore, this provides an increase in molecular complexity by the creation of an additional stereogenic center as well as installation of a synthetically valuable and versatile functionality.

The initially formed Pd-TMM complex 3a equilibrates rapidly to the most stabilized species $\mathbf{3 b},{ }^{6}$ which then adds across the activated double bond of $\mathbf{1}$ to form the exo-

methylenecyclopentane (Scheme 1). Our initial experiments with hexamethylphosphorous triamide (HMPT) as ligand for palladium showed that the desired cycloadduct formed in excellent yield as a cis/trans-mixture (Table 1, entry 1). A screen to elucidate the influence of the oxindole nitrogen substituent with our previously utilized ligand $\mathbf{L 1}, 3 \mathrm{a}$ revealed that electron withdrawing groups significantly improved the reactivity (entries 5-9). Among them, the methoxycarbonyl group provided the optimal balance between reactivity, selectivity and ease of removal. In all these cases $\mathbf{L} 1$ gave predominantly the cis-cyclopentane 5 (1:3 ratio for entry 9). This contrasts the reaction with HMPT as ligand (entry 1), where a 2:1 ratio favoring the corresponding trans-product $\mathbf{4}$ was observed. Our attempts to optimize the conditions for the formation of both diastereomers resulted in good diastereo- and excellent enantioselectivities for either trans-4 (95\% ee and 4.3:1 $d r$ with L3, entry 16) and cis-5 (99\% $e e$ and 1:6.2 $d r$ with $\mathbf{L 2}$, entry 17$).{ }^{7}$ This remarkable divergence of $\mathbf{L} \mathbf{2}$ and $\mathbf{L 3}, 8$ differing only by the position of their naphthyl-substituents on the pyrrolidine part of the ligand, might be rationalized as depicted in Scheme 1: The bulky 1-naphthyl-substituents of $\mathbf{L 3}$ preferentially orient the aromatic oxindole part of the substrate $\mathbf{1}$ under the BINOL portion of the ligand. The 2-naphthyl-substituents of $\mathbf{L} \mathbf{2}$ are shielding an area closer to the phosphorus center of the ligand, favoring an orientation of the oxindole benzene ring away from the BINOL-portion of the ligand.
\end{abstract}

bmtrost@stanford.edu .

Supporting Information Available: Experimental procedures and characterization data for new compounds (PDF). This material is available free of charge via the Internet at http://pubs.acs.org. 
With these conditions elaborated, we then turned our attention towards the scope of the reaction as summarized in Table 2. Variation of the substituents of the oxindole portion had little influence on the ee (85-96\% with $\mathbf{L 3}$ for trans-4 and 92-99\% with $\mathbf{L 2}$ for cis-5).
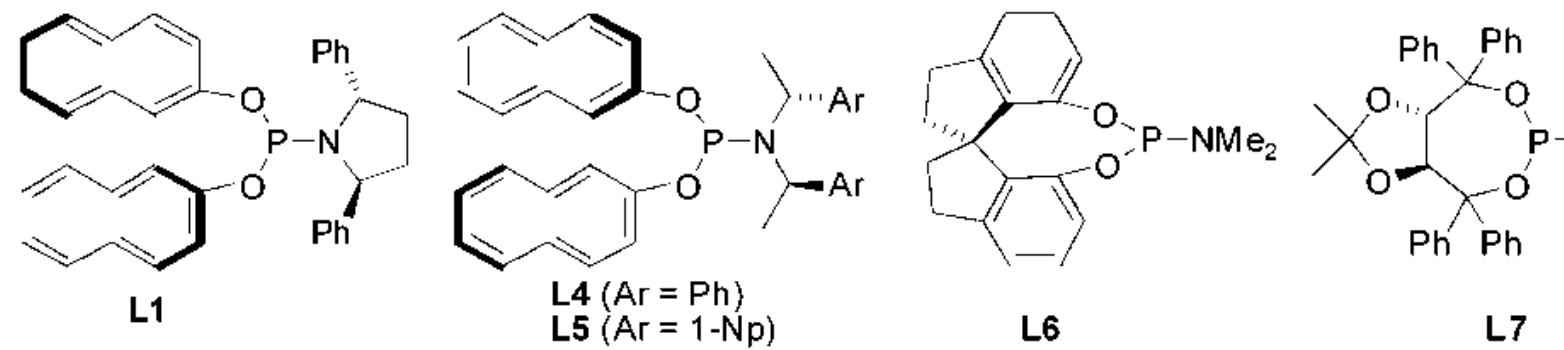

However, the diastereoselectivity is sensitive to the benzenoid substitution pattern, wherein $\mathbf{L} 2$ gave optimal dr with no substitution (entry 1) and $\mathbf{L 3}$ gave optimal dr with the more highly substituted systems (entries 2, 4 and 5). An X-ray crystal structure analysis of 6-chlorosubstituted cycloadduct $\mathbf{5 b}$ (entry 2 ) unambiguously allowed the determination of the absolute configuration to be $R$ at $\mathrm{C} 3$. Exchanging the oxindole residue by the related benzofuranone 1f (entry 6) gave comparable results as illustrated by the parent substrate 1a (entry 1).

We also explored the influence of an unsymmetrical substitution pattern on both sides of the double bond, thus creating a third stereocenter in the cycloadduct (Table 3). A smooth addition was observed even with the sterically demanding trisubstituted olefins bearing a $t$-butyl group $(\mathbf{1 g}, 1 \mathrm{~h}$ entry 1 and 2$)$. The observed stereochemistry at $\mathrm{C} 1$ and $\mathrm{C} 2$ of the resulting cycloadducts $\mathbf{4 g} / \mathbf{4 h}$ and $\mathbf{5 g} / \mathbf{5 h}$ reflect the double bond geometry of the substrate, ${ }^{9}$ supporting our proposed approach depicted in Scheme $1 .{ }^{10}$ However, the observed ee's with $\mathbf{L 3}$ were only modest, compared to the reaction with $\mathbf{L} \mathbf{2}$ which still proceeded in high selectivity (entry 1 and 2). Electron rich enol ethers (1ii, entry 3 ) are tolerated as well as substrates bearing an additional electron withdrawing ethyl ester group on the double bond (1jj, entry 4). ${ }^{11}$ A substrate with a fully unsymmetrical tetrasubstituted double bond formed the expected cyclopentane with two adjacent all carbon quaternary stereogenic centers (1k entry 5). ${ }^{12}$ With this highly hindered substrate the use of the more reactive ligand $\mathbf{L} \mathbf{2}$ was mandatory to maintain complete conversion. Interestingly - regardless of the used ligand - the trans-adduct is formed preferentially.

In summary, we have demonstrated a catalytic asymmetric palladium-catalyzed [3+2] cycloaddition with cyano-substituted Pd-TMM-complexes leading to spirocyclic oxindolic cyclopentanes. Remarkably, $\mathbf{L} 2$ and $\mathbf{L 3}$ complement each other by providing the opposite diastereomers of the cycloadduct. The reaction proceeds with sterically demanding olefins under mild conditions generating arrays of up to three stereogenic centers with excellent yields and enantiomeric excesses. Further extension of the reaction scope and its application in the synthesis of complex target molecules using cycloadducts such as $\mathbf{4 d}$ and $\mathbf{4 e}$ of Table 2 are ongoing projects in our laboratory.

\section{Supplementary Material}

Refer to Web version on PubMed Central for supplementary material. 


\section{Acknowledgement}

We thank the NSF and the NIH (GM13598) for their generous support of our programs. N. C. is a Feodor-Lynen fellow of the Alexander von Humboldt Foundation. We thank Dr. V. G. Young, Jr. from the University of Minnesota for the X-ray crystal structures and Johnson Matthey for generous gifts of palladium salts.

\section{References}

(1). Lautens M, Klute W, Tam W. Chem. Rev 1996;96:49. [PubMed: 11848744]

(2)(a). Trost BM. Angew. Chem. Int. Ed 1986;25:1. (b) Trost BM. Pure Appl. Chem 1988;60:1615. (c) ChanDTKobayashiSJørgensenKACycloaddition Reactions in Organic Synthesis20025784WileyVCHWeinheim and references cited therein.

(3)(a). Trost BM, Stambuli JP, Silverman SM, Schwörer U. J. Am. Chem. Soc 2006;128:13328. [PubMed: 17031924] (b) Yamamoto A, Ito Y, Hayashi T. Tetrahedron Lett 1989;30:375.

(4). Trost BM, Cramer N, Bernsmann H. J. Am. Chem. Soc 2007;129:3086. [PubMed: 17315880]

(5). Trost BM, Nanninga TN, Satoh T. J. Am. Chem. Soc 1985;107:721.

(6). Gordon DJ, Fenske RF, Nanninga TN, Trost BM. J. Am. Chem. Soc 1981;103:5974.

(7). The parent unsubstituted TMM-donor gave under identical reaction conditions a quant. yield and $71 \%$ ee with $\mathbf{L 2}$.

(8). Trost, BM.; Silverman, SM.; Stambuli, JP. J. Am. Chem. Soc.

(9). Partial equilibration of the double bond prior to the cycloaddition occurs when using the more nucleophilic HMPT as ligand.

(10). With this substrate class, a scrambling of the double bond geometry through bond rotation of an intermediate species is not observed, which is in accordance with both a stepwise mechanism and fast ring closure (Trost BM, Chan DMT. J. Am. Chem. Soc 1980;102:6359. Trost BM, Chan DMT. J. Am. Chem. Soc 1983;105:2326.) or a concerted mechanism described by Singleton (Singleton DA, Schulmeier BE. J. Am. Chem. Soc 1999;121:9313.),

(11). Double bond migration of preferentially one product isomer occurred.

(12). Peterson EA, Overman LE. Proc Natl Acad Sci USA 2004;101:11943. [PubMed: 15232003] 


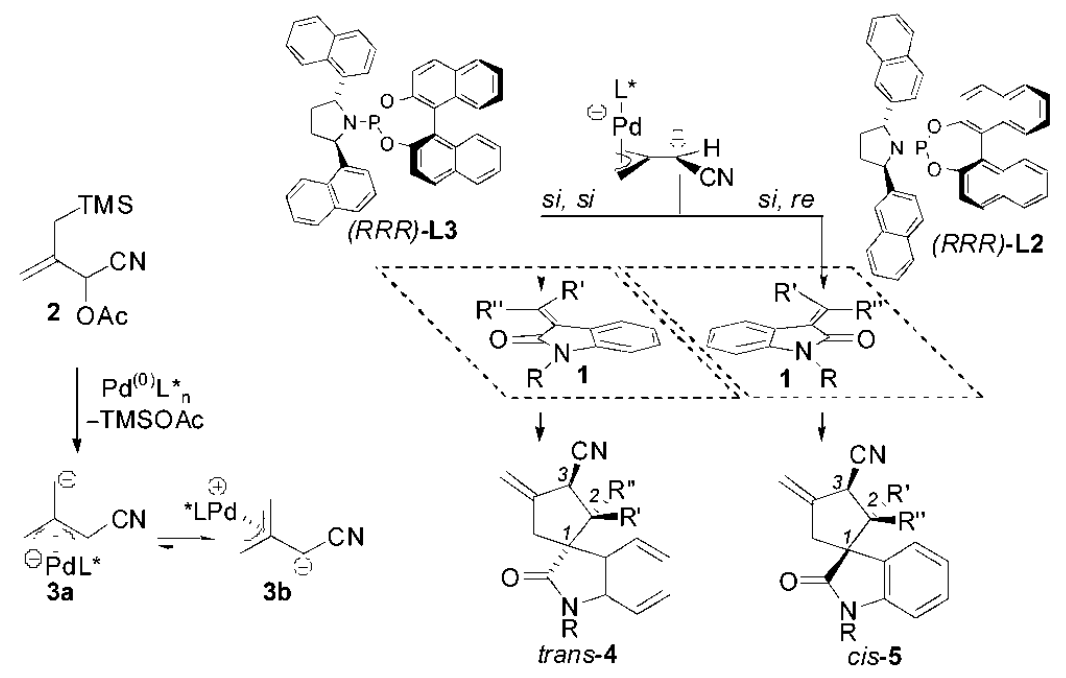

Scheme 1. 


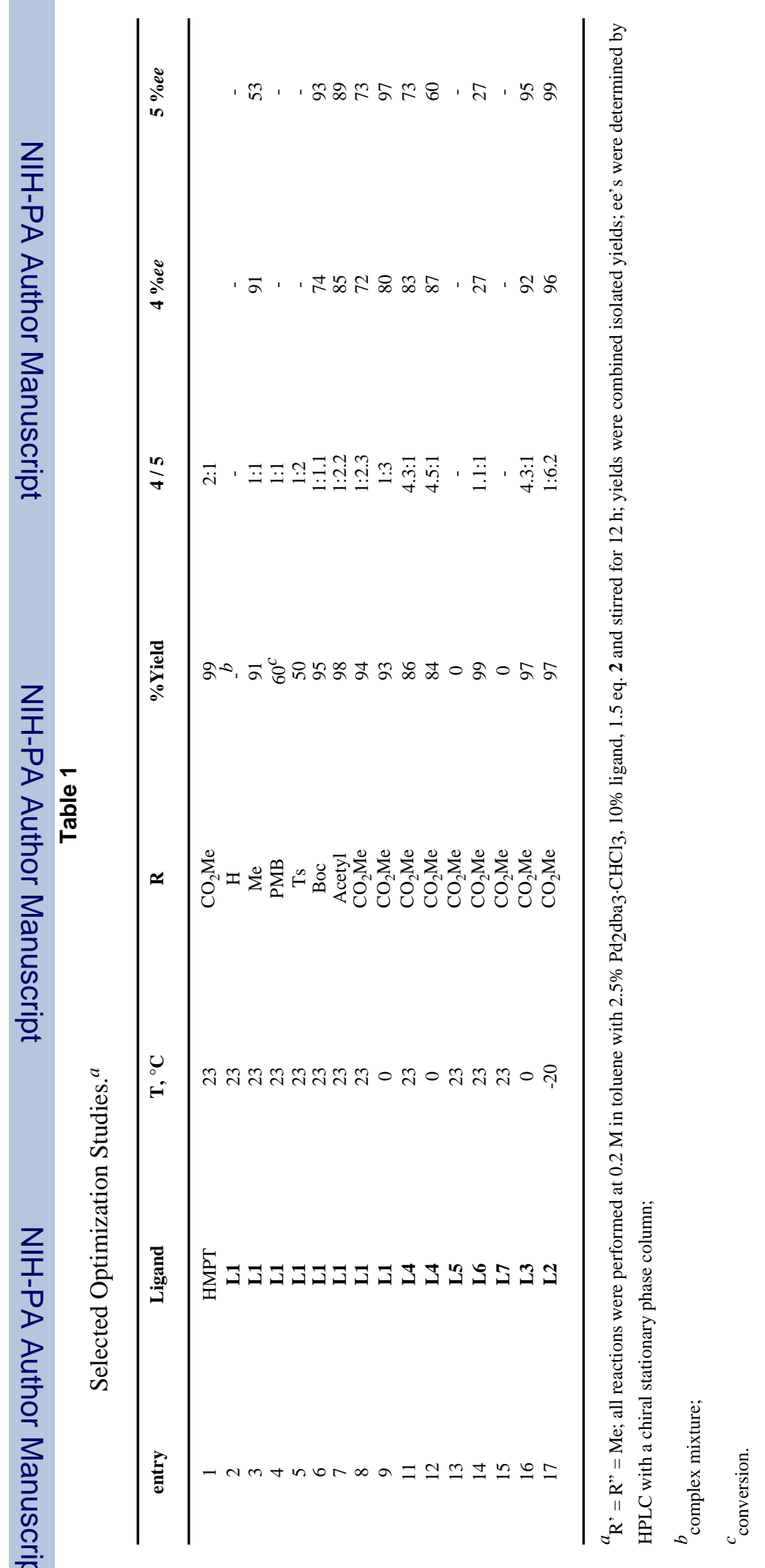




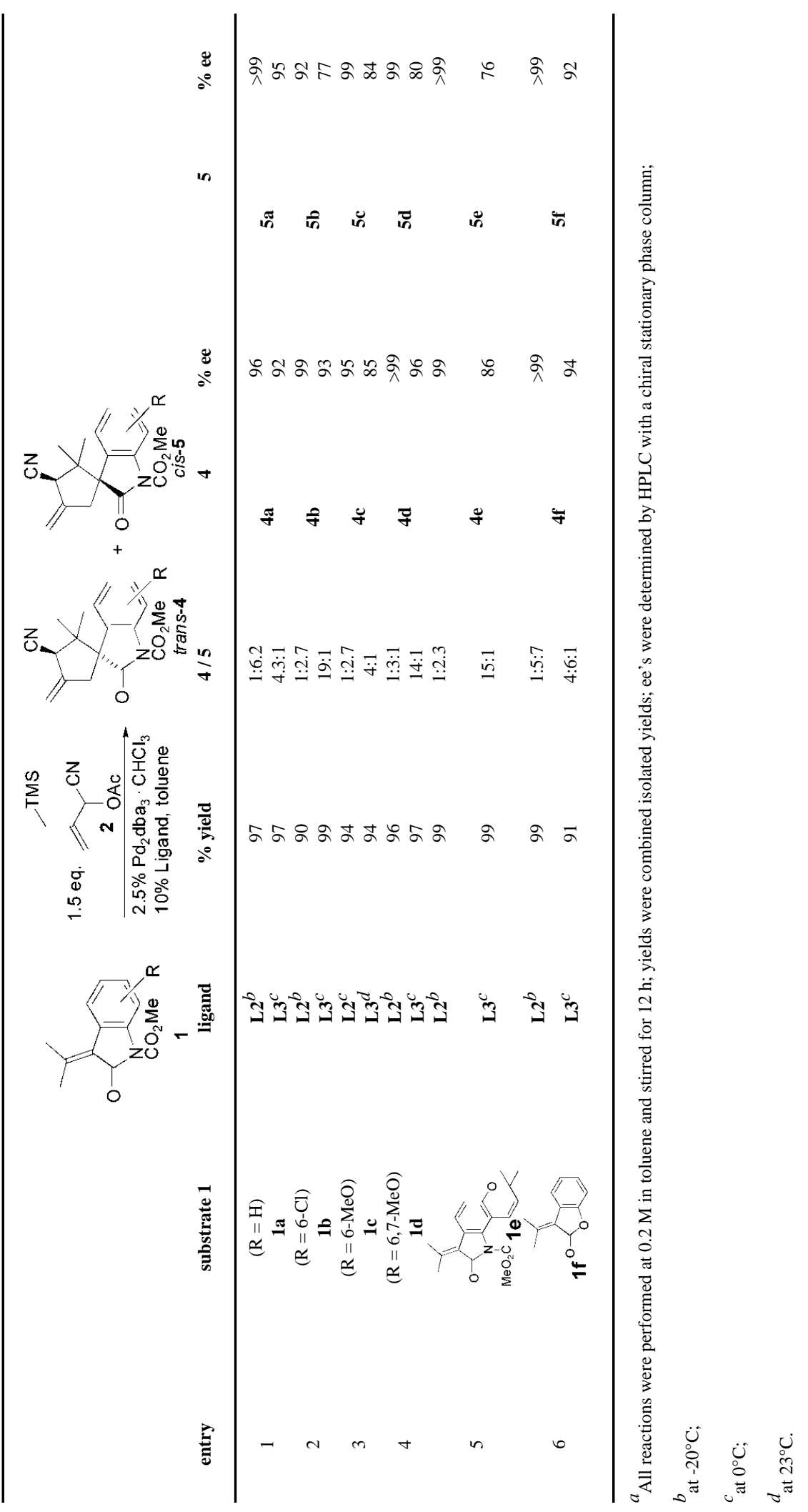

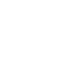




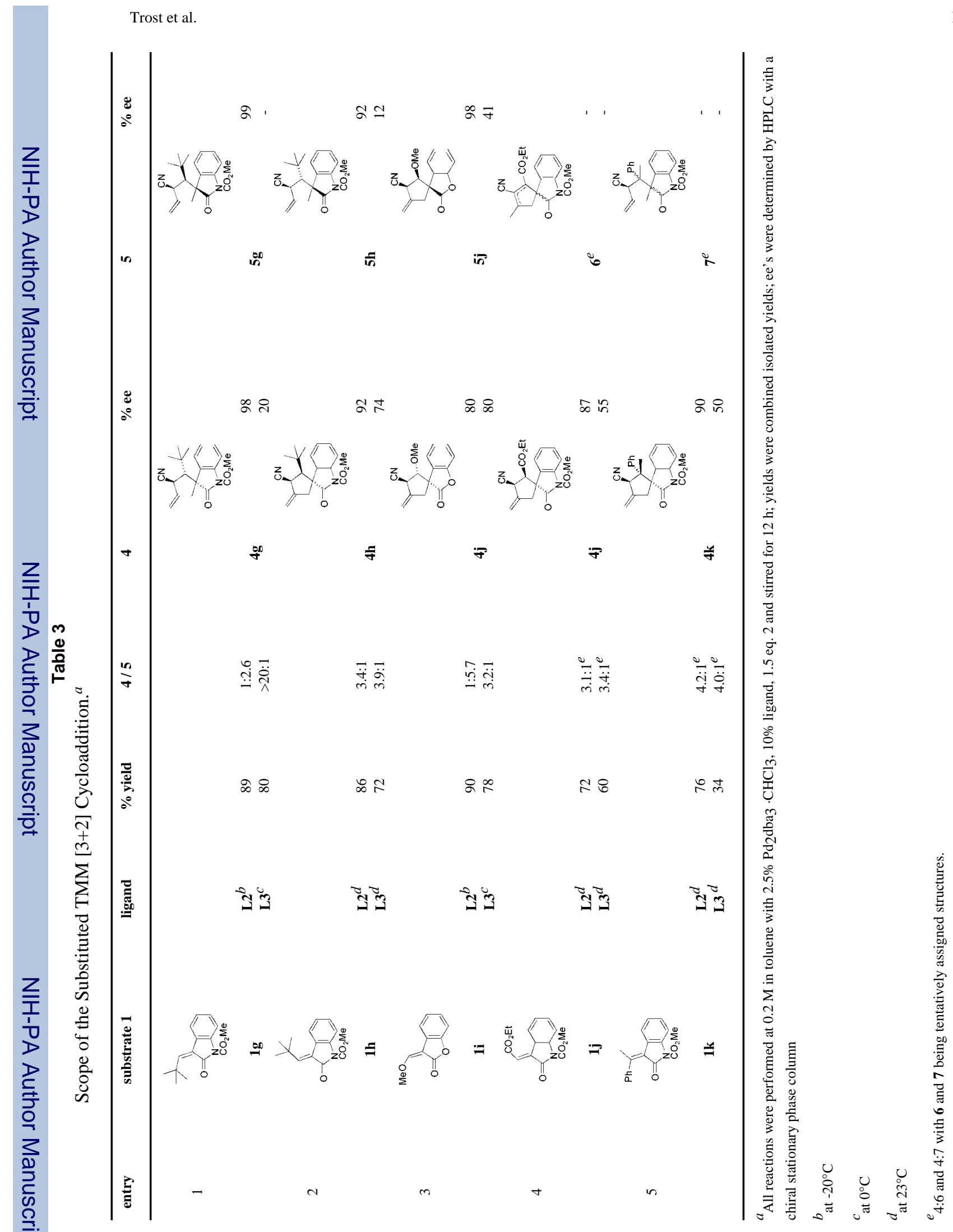

J Am Chem Soc. Author manuscript; available in PMC 2009 January 9. 